The Classical Quarterly

http://journals.cambridge.org/CAQ

Additional services for The Classical Quarterly:

Email alerts: $\underline{\text { Click here }}$

Subscriptions: $\underline{\text { Click here }}$

Commercial reprints: Click here

Terms of use : $\underline{\text { Click here }}$

\title{
ARISTOTLE, METAPHYSICS Z 1029a6
}

LUCA GILI

The Classical Quarterly / Volume 62 / Issue 01 / May 2012, pp 426 - 427

DOI: 10.1017/S0009838811000462, Published online: 24 April 2012

Link to this article: http://journals.cambridge.org/abstract S0009838811000462

How to cite this article:

LUCA GILI (2012). ARISTOTLE, METAPHYSICS Z 1029a6. The Classical Quarterly, 62, pp 426-427 doi:10.1017/ S0009838811000462

Request Permissions : $\underline{\text { Click here }}$ 


\section{ARISTOTLE, METAPHYSICS Z 1029a6 ${ }^{1}$}

W.D. Ross's edition of the Metaphysics has the following passage: $\tau$ oı

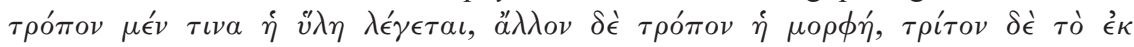

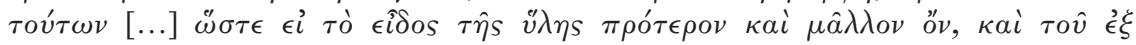

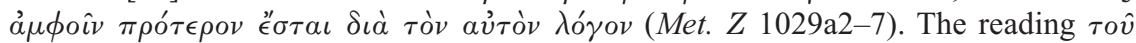
$\mathfrak{\epsilon}^{\xi} \dot{\alpha} \mu \phi \circ \hat{\imath} \nu$ is supported by one branch of the manuscript tradition (MS Vindob. Phil. gr. C and MS Parisinus gr. 1853); the other branch, which we know mostly on the basis of MS Laurentianus 87.12, presents the interesting variant $\tau \dot{o} \dot{\epsilon}^{\prime} \xi \dot{\alpha} \mu \phi o \hat{\imath} \nu$, but the reading is a correction of an original $\tau o \hat{v} \hat{\epsilon}^{\prime} \xi \dot{\alpha} \mu \phi o \hat{\imath}$. The difference between the two readings is philosophically worthwhile: the printed reading supports the idea that if form is prior to matter, then it must be prior to the composite of matter and form, because matter is part of the composite. Hence if the true substance is what is prior, then individual form is the true substance. On the other hand the reading $\tau \dot{o} \hat{\epsilon}^{\prime} \xi \alpha_{\mu} \mu \phi o \hat{\nu}$ suggests that if form is prior to matter, then also what is composite by form and something different from form (namely matter), is prior to matter. Such a reading does not exclude the possibility that individual form is the true substance, but it makes room also for the composite of matter and form to be a possible candidate for substance. From these considerations it can be argued that a detailed discussion of the choice between these readings is needed in order to achieve a clearer understanding of Aristotle's philosophical claims.

From the inspection of the manuscript it is impossible to establish whether the correction of Laurentianus 87.12 ( $\tau \dot{o} \hat{\epsilon} \dot{\xi} \dot{\alpha} \mu \phi o \hat{\iota} \nu$ ) may be attributed to a reader who has corrected the text following presumably his own philosophical opinions or to the copyist (and hence it would be reasonable that in his copy there was the reading $\tau \grave{o} \mathfrak{\epsilon}^{\prime} \xi \alpha_{\alpha} \mu \phi o \hat{\nu}$, that he firstly understood wrongly). From these considerations it seems correct to choose the reading $\tau o \hat{v} \hat{\epsilon}^{\prime} \xi \dot{\alpha} \mu \phi o \hat{\nu}$, which has been preferred by Ross and by all modern editions of the Metaphysics. An alternative reading is suggested by Alexander's De anima, in which there is an indirect reference to

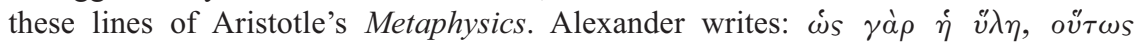

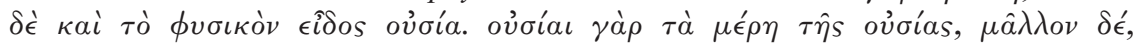

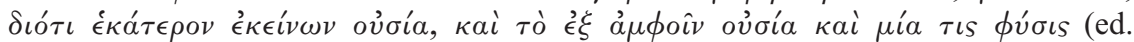
Bruns, 6. 2-4). The commentator is not simply asking what the term 'substance' can refer to, but he is also presenting a hierarchy among the possible candidates

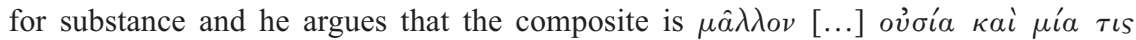
$\phi v ́ \sigma \iota s$. Alexander of Aphrodisias, as is well known, looked for various copies of Aristotle's texts and he often discussed in his commentaries the variants which he found (cf. Alex. Aphr. in An. pr. 9.10-20, 144.5-6, 151.15, 210.30-4, 304.13-17,

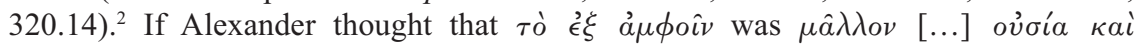

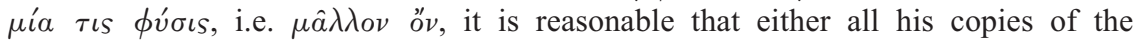
Metaphysics presented the reading $\tau \dot{o} \mathfrak{\epsilon}^{\prime} \xi \alpha \dot{\alpha} \mu \phi \hat{\imath} \nu$ or he thought that this reading was the better one, even though it was not supported by all his copies of the text.

\footnotetext{
${ }^{1}$ I am grateful to Giuseppe Pezzini, to John Wilkins and to the anonymous referee of this journal for helpful comments on a previous draft of this note. Remaining shortcomings are solely my responsibility.

${ }^{2}$ A detailed discussion of Alexander's philology may be found in P. Moraux, 'Les débuts de la philologie aristotélicienne', in G. Cambiano, Storiografia e dossografia nella filosofia antica (Turin, 1986), 127-47.
} 
This argument has shown that $\tau \dot{o} \dot{\epsilon} \xi \dot{\alpha} \mu \phi o \hat{\imath} \nu$ is a variant of the reading printed by modern editors, at least since Alexander's times. I think that it is possible to go further. Alexander usually chose the readings of Aristotle's texts according to his own interpretation of Aristotelian philosophy (cf. Alex. Aphr. in Met. 54.11-13, 186.3-187.6, 223.23-8, 251.2-6, 267.14-21, 357.24-30, 368.7-15). But the reading $\tau \dot{o} \mathfrak{\epsilon}^{\prime} \xi \dot{\alpha} \mu \phi o \hat{\imath} \nu$ favours the idea that the true substance is the composite, whilst according to Alexander the individual form, as in the case of human intellect, is substance in a more proper sense. Therefore it is possible to suppose that if he had had the opportunity, he would have chosen the reading $\tau o \hat{v} \dot{\epsilon} \dot{\xi} \dot{\alpha} \mu \phi o \hat{\iota} \nu$ in his lost commentary and in his other works, as in the extant passage from his De anima, which is presumably a quotation from Metaphysics $Z 3$. If he $\operatorname{did}$ not do that, it seems quite reasonable to conclude that in his time either only one reading was attested, namely $\tau \dot{o} \grave{\epsilon}^{\prime} \xi \dot{a} \mu \phi o \hat{\imath} \nu$, or that only this reading was preserved in Alexander's copies of the Metaphysics. This argument definitely rules out the possibility that $\tau \grave{o} \grave{\epsilon}^{\prime} \xi \alpha \dot{\alpha} \mu \phi \hat{\imath} \nu$ is a medieval correction of a unanimous testimony of both branches of the manuscript tradition. Is it the authentic reading? I think that such a conclusion could be precipitate: even if it is reasonable to suppose that Alexander had only this reading, it is unsound method to exclude the possibility that in his time there were other readings not available to him, which preserved the authentic text. A possible criterion for the selection of the authentic reading could be the coherence of the philosophical doctrine expressed by Metaphysics $Z$ $1029 \mathrm{a} 6$ with the general theory of substance advanced by Aristotle in Metaphysics $Z$. Unfortunately there is no agreement among scholars about the right interpretation of this book: it has been said either that true substance is individual form, or that true substance is the composite of matter and form. Hence both readings can be defended on the basis of those conflicting interpretations. ${ }^{3}$ However, I think that such a doubt about the right reading is philosophically worthwhile, because it rules out the possibility of taking Metaphysics $Z 1029 \mathrm{a} 6$ - with the reading of modern editions - as evidence in favour of the interpretation of substance as individual form. As a consequence, such a doubt about the right reading of this passage turns out to be puzzling for Aristotle's interpreters and I hope that future inquiries may offer a solution to the general problem of the interpretation of Book $Z$, so that there will also be a reasonable foundation for argument in favour of one of the two possible readings of Metaphysics $Z$ 1029a6.

Università di Padova/Scuola Normale Superiore, Pisa

LUCA GILI

luca.gili@studenti.unipd.it doi:10.1017/S0009838811000462

${ }^{3}$ Cf. M. Frede and G. Patzig, Aristoteles. "Metaphysik Z". Zweiter Band. Kommentar (Munich, 1988), 40-1. Frede and Patzig take individual form as the true substance and therefore they coherently consider the printed reading as the authentic one. 